\title{
Childhood-onset Leber hereditary optic neuropathy
}

\section{Majander, Anna}

2017-11

\begin{abstract}
Majander , A , Bowman , R , Poulton , J , Antcliff , R J , Reddy, M A, Michaelides , M , Webster , A R , Chinnery , P F , Votruba , M , Moore , A T \& Yu-Wai-Man , P 2017 , ' Childhood-onset Leber hereditary optic neuropathy ' , British Journal of Ophthalmology , vol. 101 , no. 11 , pp. 1505-1509 . https://doi.org/10.1136/bjophthalmol-2016-310072
\end{abstract}

http://hdl.handle.net/10138/232822

https://doi.org/10.1136/bjophthalmol-2016-310072

cc_by

publishedVersion

Downloaded from Helda, University of Helsinki institutional repository.

This is an electronic reprint of the original article.

This reprint may differ from the original in pagination and typographic detail.

Please cite the original version. 


\title{
Childhood-onset Leber hereditary optic neuropathy
}

\author{
Anna Majander, ${ }^{1}, 2,3$ Richard Bowman, ${ }^{4}$ Joanna Poulton, ${ }^{5}$ Richard J Antcliff, ${ }^{6}$ \\ M Ashwin Reddy, ${ }^{2}$ Michel Michaelides ${ }^{1,2}$ Andrew R Webster, ${ }^{1,2}$ Patrick F Chinnery, ${ }^{7,8,9}$ \\ Marcela Votruba, ${ }^{10}$ Anthony T Moore, ${ }^{1,2,11}$ Patrick Yu-Wai-Man ${ }^{1,2,7,12}$
}

\begin{abstract}
- Additional material is published online only. To view please visit the journal online (http://dx.doi.org/10.1136/ bjophthalmol-2016-310072).

For numbered affiliations see end of article.
\end{abstract}

\section{Correspondence to} Dr Anna Majander, UCL Institute of Ophthalmology and Moorfields Eye Hospital, 162 City Road, London, EC1V 2PD London, UK; and Department of Ophthalmology, Helsinki University Hospital, and University of Helsinki, P.O. Box 220, Helsinki FI-00029, Finland; anna.majander@hus.fi

Received 15 December 2016 Revised 20 February 2017 Accepted 23 February 2017 Published Online First 17 March 2017

\section{CrossMark}

To cite: Majander $A$ Bowman R, Poulton J, et al. Br J Ophthalmol 2017;101:1505-1509.

\section{ABSTRACT}

Background The onset of Leber hereditary optic neuropathy (LHON) is relatively rare in childhood. This study describes the clinical and molecular genetic features observed in this specific LHON subgroup. Methods Our retrospective study consisted of a UK paediatric LHON cohort of 27 patients and 69 additional cases identified from a systematic review of the literature. Patients were included if visual loss occurred at the age of 12 years or younger with a confirmed pathogenic mitochondrial DNA mutation: $\mathrm{m} .3460 \mathrm{G}>\mathrm{A}$, m.11778G $>$ A or m.14484T>C.

Results In the UK paediatric LHON cohort, three patterns of visual loss and progression were observed: (1) classical acute (17/27, 63\%); (2) slowly progressive $(4 / 27,15 \%)$; and (3) insidious or subclinical (6/27, $22 \%)$. Diagnostic delays of 3-15 years occurred in children with an insidious mode of onset. Spontaneous visual recovery was more common in patients carrying the m.3460G $>A$ and $m .14484 T>C$ mutations compared with the m.11778G $>$ A mutation. Based a meta-analysis of 67 patients with available visual acuity data, 26 $(39 \%)$ patients achieved a final best-corrected visual acuity $(B C V A) \geq 0.5$ Snellen decimal in at least one eye, whereas $13(19 \%)$ patients had a final BCVA $<0.05$ in their better seeing eye.

Conclusions Although childhood-onset LHON carries a relatively better visual prognosis, approximately 1 in 5 patients will remain within the visual acuity criteria for legal blindness in the UK. The clinical presentation can be insidious and LHON should be considered in the differential diagnosis when faced with a child with unexplained subnormal vision and optic disc pallor.

\section{INTRODUCTION}

Leber hereditary optic neuropathy (LHON) (OMIM 535000) is a mitochondrial disorder that classically presents with acute or subacute bilateral loss of central vision in young adult men. ${ }^{1-3}$ About $90 \%$ of patients carry one of the three major disease-causing LHON mitochondrial DNA (mtDNA) mutations (MTND1m.3460G>A, MTND4m.11778G $>\mathrm{A}$ and MTND6m.14484T $>$ C), all of which encode for critical complex I subunits of the mitochondrial respiratory chain. ${ }^{4}$ The greater availability of molecular genetic testing has broadened the phenotypical spectrum associated with LHON to include patients with more slowly progressive visual deterioration exceeding 6 months in duration, and those with an insidious/subclinical course characterised by the incidental discovery of subnormal vision and optic atrophy in the absence of overt visual symptoms. ${ }^{15}$ Although disease conversion can occur anywhere from the first to the eight decade of life, the peak age of onset of visual loss among LHON carriers is $20-30$ years old. ${ }^{14}$ Childhood-onset disease is relatively rare and less than $10 \%$ of patients were 12 years old or younger at the time of diagnosis in previously published case series. ${ }^{16-10}$ Although there are limited data on this important patient subgroup, the phenotype seems distinct from classical adult-onset LHON with atypical patterns of vision loss and a better visual prognosis as reported in a previously published study of 18 patients with childhood-onset LHON. ${ }^{7}$

The aim of our study was to describe the clinical and molecular genetic characteristics associated with childhood-onset LHON, in particular the disease course and visual prognosis to better inform genetic counselling. We retrieved data for all eligible patients with LHON that were seen at three major diagnostic centres for inherited optic neuropathies in the UK. This UK paediatric LHON cohort was then combined with additional cases identified from a systematic review of the literature to generate a comprehensive meta-analysis of childhood LHON.

\section{PATIENTS AND METHODS \\ Study population}

This is a retrospective observational study approved by the local ethics committee at Moorfields Eye Hospital and it conformed to the standards set by the Declaration of Helsinki. Patients with LHON with disease onset at the age of 12 years or younger were identified from the clinical and genetic databases of the three main national diagnostic centres for inherited optic neuropathies in the UK (London, Oxford and Newcastle upon Tyne). We only included patients who carried one of the three canonical pathogenic mtDNA mutations, that is, m.3460G $>A$, m.11778G $>A$ and m.14484T $>$ C. Additional clinical information where relevant was sought from the original referring clinicians. Best-corrected visual acuities (BCVAs) at disease onset, at the nadir and at the last follow-up clinic visit were recorded. Patients were subclassified into three groups based on the mode of onset and progression of vision loss: (1) acute, if visual acuity deteriorated rapidly reaching the nadir within 6 months from disease onset; (2) slowly progressive, if visual deterioration occurred over a period exceeding 6 months; and (3) insidious or subclinical, if the patient was clinically asymptomatic at the time that a diagnosis of optic atrophy or subnormal vision was made, and there was no change in visual acuity during subsequent follow-ups. ${ }^{1} 7$ Spontaneous visual recovery was defined as an improvement of BCVA by two lines or more on the ETDRS chart or from off-chart to on-chart visual acuity (0.05 
Snellen decimal (SD)). A binocular visual acuity of at least 0.5 (6/ 12 ) is the minimum standard for driving in the UK (https://www. gov.uk/driving-eyesight-rules, accessed on 8 November 2016) and below $0.05(3 / 60)$ is the legal definition of registrable blindness in the UK (https://www.gov.uk/government/publications/ guidance-published-on-registering-a-vision-impairment-as-adisability, accessed on 8 November 2016).

When available, spectral-domain optical coherence tomography (SD-OCT) data were retrieved from the database of the Spectralis (Heidelberg Engineering, Heidelberg, Germany) and Cirrus HD-OCT 4000 (Carl Zeiss Meditec, Dublin, California, USA) platforms, and compared with the normative data described elsewhere. ${ }^{11} 12$

\section{Systematic literature review}

A comprehensive literature search was conducted using the search terms 'LHON', 'Leber hereditary optic neuropathy'or 'Leber's hereditary optic neuropathy' and 'child', 'childhood', 'paediatric' or 'paediatric' on PubMed (https://www.ncbi.nlm.nih.gov/ pubmed/, accessed on 8 November 2016). We also reviewed all the papers that included previously published publications on childhood LHON in their reference lists. A patient with LHON was included in our meta-analysis only if there was confirmation of the m.3460G $>$ A, m.11778G $>$ A or m.14484T $>C$ mtDNA mutation, and disease onset was clearly stated as being before the age of 12 years or younger. None of the patients included in the historical case series was present in the UK paediatric LHON cohort. Due to the retrospective nature of our systematic literature review, more detailed clinical information regarding visual acuity and disease progression was not available for 29 of the 69 eligible patients included in our historical case series.

\section{Statistical analysis}

The Kruskal-Wallis test and Mann-Whitney $U$ independent samples test were used for comparing the age at onset between the LHON genotypes and the distribution of retinal layer thickness in LHON and control eyes, respectively. The Spearman's rank correlation test was used to assess for the strength of dependence between BCVA and retinal layer thickness (IBM Statistical Package of Social Sciences (SPSS) 22 V.100).

\section{RESULTS}

\section{UK paediatric LHON cohort}

The UK paediatric LHON cohort included 27 patients who were $2-11$ years old (mean $=6.9$ years, $S D=2.9$ years) at the time of onset of visual loss or when subnormal visual acuity or optic disc pallor first became apparent (table 1). Thirteen patients (48\%) carried the m.11778G $>$ A mutation, seven patients $(26 \%)$ the m.3460G $>A$ mutation and seven patients (26\%) the m.14484T >C mutation (table 2). Patients 24-27 belonged to the same family and out of five affected family members, four of them developed visual loss before the age of 6 years. There was a known family history of LHON in 19 probands (70\%). The male:female ratio varied between 2.5 and 3.3 for the three primary LHON mtDNA mutations with an overall male:female ratio of 3.0. There was no statistically significant difference in the age of disease onset between the LHON genotypes (Kruskal-Wallis test, $\mathrm{p}=0.831$ ).

The majority of patients $(17 / 27,63 \%)$ experienced acute or subacute visual loss with the nadir being reached within 6 months of first disease onset. This mode of presentation was the most common in children harbouring the m.3460G $>$ A mutation $(6 / 7,86 \%)$. In four patients $(15 \%)$, visual acuity deteriorated slowly over a period extending up to 2 years. Three patients in this subgroup carried the m.14484T $>C$ mutation and one the m.11778G $>$ A mutation. There was an unexpectedly large number of children $(6 / 27,22 \%)$ with insidious or subclinical vision loss in the UK paediatric LHON cohort. Subnormal vision or optic disc pallor were detected during the first 2 years of life $(n=4)$ or after failing the preschool visual screening assessment $(n=2)$, which is mandatory in the UK for all 4-5-year-olds (table 1). None of these children demonstrated or were suspected of having impaired visual performance during their early years and no visual deterioration occurred on subsequent follow-up. Molecular genetic confirmation of LHON in this insidious/subclinical group was markedly delayed between 3 years and 15 years due to the atypical presentation.

The mean final BCVA in the whole group of patients with childhood-onset $\mathrm{LHON}$ was $0.39 \mathrm{SD}(\mathrm{SD}=0.38$, range $=$ light perception-1.2 SD, median $=0.25$ ) with a mean disease duration of 18 years $(\mathrm{SD}=16$ years, range $=1-56$ years, median $=16$ years). BCVA was $\geq 0.5$ in 20/54 (37\%) eyes and $14 / 27(52 \%)$ patients had at least 1 eye with BCVA $\geq 0.5$. Conversely, BCVA was $<0.05$ in 11/54 (20\%) eyes and 5/27 (19\%) patients met the legal definition of blindness with a BCVA $<0.05$ in their better seeing eye. The $\mathrm{m} .11778 \mathrm{G}>\mathrm{A}$ mutation was associated with a worse visual outcome compared with the m.3460G $>$ A and $\mathrm{m} .14484 \mathrm{~T}>\mathrm{C}$ mutations (table 2 and figure 1$)$. Ten $(37 \%)$ patients had asymmetrical final BCVA with a difference $\geq 2$ lines on the ETDRS chart, and this was associated with: (1) asymmetrical visual loss in the acute stage $(n=2) ;(2)$ asymmetrical visual recovery following an acute disease onset $(n=2)$; (3) slowly progressive visual loss $(\mathrm{n}=3)$; and (4) an insidious/subclinical course $(n=3)$. Patient 26, who harboured the m.14484T $>$ C mutation, presented with slowly progressive visual deterioration in only one eye. In patients presenting with acute LHON, spontaneous visual recovery occurred in 20/34 (59\%) eyes and $16(80 \%)$ of the recovered eyes achieved a BCVA $\geq 0.5$. The mean time to recovery was 29 months $(S D=18$ months, range $=9-60$ months) and there were no significant differences between mutation subgroups (m.3460G $>$ A, mean $=28$ months; m.11778G $>$ A, mean $=27$ months; m.14484T $>$ C, mean=32 months; KruskalWallis test, $\mathrm{p}=0.958)$. Visual outcome was bimodal in the acute LHON group with a BCVA $\geq 0.5$ in $17 / 34$ (50\%) eyes and $<0.05$ in $10 / 34(29 \%)$ eyes (figure 2 ). The majority of eyes for patients classified as having slowly progressive $(5 / 8,63 \%)$ or insidious/subclinical $(11 / 12,82 \%)$ LHON had BCVA $<0.5$.

SD-OCT imaging of the optic nerve head was available for 26 eyes of 13 patients. There was a significant reduction in the average peripapillary retinal nerve fibre layer (RNFL) thickness ranging from $49.0 \%$ to $58.4 \%$ compared with control values. On subgroup analysis, there was no significant correlation between BCVA and peripapillary RNFL thickness in any of the individual quadrants (data not shown). Perifoveal volumetric retinal SDOCT scans were available for 10 eyes of five patients. Retinal thickness was significantly reduced in the LHON group (mean $\pm \mathrm{SD}=295.5 \pm 17.7 \mu \mathrm{m}$ ) compared with normal controls (mean $\pm \mathrm{SD}=340.8 \pm 13.3 \mu \mathrm{m}$, Mann-Whitney U test, $\mathrm{p}<0.001)$. This was specifically due to marked thinning of the ganglion cell layerinner plexiform layer (GCL-IPL) complex in the LHON group $($ mean $\pm \mathrm{SD}=43.2 \pm 2.9 \mu \mathrm{m})$ compared with normal controls (mean $\pm \mathrm{SD}=93.5 \pm 7.8 \mu \mathrm{m}$, Mann-Whitney $U$ test, $\mathrm{p}<0.001$ ). There was a statistically significant correlation between BCVA and the remaining GCL-IPL thickness (Spearman's $r=-0.773$, $\mathrm{p}=0.009$, online supplementary figure $\mathrm{S} 1$ ).

\section{Meta-analysis of childhood-onset LHON}

Our systematic review of the literature identified 69 patients with LHON with onset of vision loss at the age of 12 years or 
Table 1 Demographics and clinical features of patients included in the UK paediatric LHON cohort

\begin{tabular}{|c|c|c|c|c|c|c|c|c|c|}
\hline \multirow[b]{2}{*}{ Patient } & \multirow[b]{2}{*}{ Mutation } & \multirow{2}{*}{$\begin{array}{l}\text { Family } \\
\text { history }\end{array}$} & \multirow[b]{2}{*}{$f / m$} & \multirow{2}{*}{$\begin{array}{l}\text { Age at } \\
\text { onset (years) }\end{array}$} & \multirow{2}{*}{$\begin{array}{l}\text { Mode of } \\
\text { onset }\end{array}$} & \multirow[b]{2}{*}{ Disease progression } & \multicolumn{2}{|c|}{ Final BCVA* } & \multirow{2}{*}{$\begin{array}{l}\text { Time from } \\
\text { onset (years) }\end{array}$} \\
\hline & & & & & & & RE & LE & \\
\hline 1 & 11778 & Yes & $f$ & 6 & $\mathrm{~S}$ & Gradual visual deterioration over 2 years. & 0.17 & 0.02 & 47 \\
\hline 2 & 11778 & Yes & $f$ & 8 & $A$ & No recovery. & LP & LP & 56 \\
\hline 3 & 11778 & Yes & $f$ & 9 & $A$ & No recovery. & 0.03 & 0.03 & 38 \\
\hline 4 & 11778 & Yes & $\mathrm{m}$ & 11 & $A$ & Worst BCVA: HM BE. Recovery within 12 months from onset. & 0.76 & 0.50 & 1 \\
\hline 5 & 11778 & No & $\mathrm{m}$ & 8 & A & No recovery. & $\mathrm{CF}$ & $\mathrm{CF}$ & 33 \\
\hline 6 & 11778 & No & $\mathrm{m}$ & 3 & I & Subnormal vision since birth. & 0.17 & 0.50 & 52 \\
\hline 7 & 11778 & No & $\mathrm{m}$ & 9 & A & Worst BCVA: 0.08 RE, 0.4 LE. Asymmetrical. & 0.10 & 0.50 & 18 \\
\hline 8 & 11778 & Yes & $\mathrm{m}$ & 11 & $A$ & No recovery. & 0.07 & 0.10 & 2 \\
\hline 9 & 11778 & No & $\mathrm{m}$ & 2 & I & $\begin{array}{l}\text { Subnormal vision detected when } 2 \text { years old. LHON diagnosed } \\
\text { at the age of } 8 \text { years. }\end{array}$ & 0.25 & 0.08 & 17 \\
\hline 10 & 11778 & Yes & $\mathrm{m}$ & 8 & A & No recovery. & CF & CF & 10 \\
\hline 11 & 11778 & No & $\mathrm{m}$ & 10 & A & $\begin{array}{l}\text { Worst BCVA: CF BE. Recovery within } 24 \text { months from onset. } \\
\text { Asymmetrical recovery. }\end{array}$ & 0.08 & 0.66 & 7 \\
\hline 12 & 11778 & Yes & $\mathrm{m}$ & 2 & I & $\begin{array}{l}\text { Subnormal vision detected when } 2 \text { years old. LHON diagnosed } \\
\text { at the age of } 6 \text { years with BCVA of } 0.18 \text { RE and } 0.17 \text { LE. Slow } \\
\text { visual recovery until } 10 \text { years old. }\end{array}$ & 0.35 & 0.36 & 4 \\
\hline 13 & 11778 & Yes & $\mathrm{m}$ & 2 & I & $\begin{array}{l}\text { Optic atrophy noted at the age of } 2 \text { years. LHON diagnosed at } \\
\text { the age of } 17 \text { years. }\end{array}$ & 0.40 & 0.10 & 15 \\
\hline 14 & 3460 & Yes & f & 7 & A & Worst BCVA: 0.05 BE. Recovery within 4 years from onset. & 0.79 & 0.79 & 4.5 \\
\hline 15 & 3460 & No & $f$ & 11 & A & No recovery. & $\mathrm{CF}$ & CF & 10 \\
\hline 16 & 3460 & Yes & $\mathrm{m}$ & 4 & I & Poor visual acuity noticed at preschool screening assessment. & 0.17 & 0.17 & 16 \\
\hline 17 & 3460 & No & $\mathrm{m}$ & 6 & A & Asymmetrical visual recovery. & 0.67 & 0.25 & 18 \\
\hline 18 & 3460 & Yes & $\mathrm{m}$ & 8 & A & Worst BCVA: 0.05 BE. Recovery within 12 months from onset. & 1.20 & 1.20 & 1 \\
\hline 19 & 3460 & Yes & $\mathrm{m}$ & 10 & A & Worst BCVA: HM RE, CF LE. Recovery. & 0.33 & 0.50 & 1.5 \\
\hline 20 & 3460 & No & $\mathrm{m}$ & 5 & $A$ & Worst BCVA: 0.1 BE. Recovery within 24 months from onset. & 1.00 & 1.00 & 2 \\
\hline 21 & 14484 & Yes & $f$ & 9 & $\mathrm{~S}$ & Gradual visual deterioration over 2 years. & 0.17 & 0.25 & 29 \\
\hline 22 & 14484 & Yes & $\mathrm{m}$ & 10 & A & Recovery within 9 months from onset. & 1.00 & 1.00 & 16 \\
\hline 23 & 14484 & Yes & $\mathrm{m}$ & 5 & 1 & Poor visual acuity noticed at preschool screening assessment. & 0.25 & 0.25 & 39 \\
\hline $24 \dagger$ & 14484 & Yes & $f$ & 6 & A & $\begin{array}{l}\text { Worst BCVA: } 0.02 \text { RE, } 0.2 \text { LE. Recovery within } 5 \text { years from } \\
\text { onset. }\end{array}$ & 0.91 & 1.00 & 18 \\
\hline $25+$ & 14484 & Yes & $\mathrm{m}$ & 6 & $S$ & Asymmetrical visual recovery. & 0.69 & 0.14 & 13 \\
\hline $26 t$ & 14484 & Yes & $\mathrm{m}$ & 4 & $\mathrm{~S}$ & Slowly progressive visual deterioration in the LE only. & 1.00 & 0.10 & 13 \\
\hline $27 \dagger$ & 14484 & Yes & $\mathrm{m}$ & 5 & A & $\begin{array}{l}\text { Off-chart vision (BE) at the nadir. Asymmetrical recovery } \\
\text { within 2-3 years from onset. }\end{array}$ & 0.07 & 0.67 & 28 \\
\hline
\end{tabular}

${ }^{*}$ BCVA recorded at last follow-up clinic visit in Snellen decimal.

†From the same pedigree.

A, acute; BCVA, best corrected visual acuity; BE, both eyes; CF, counting fingers at 0.25 metre; f, female; HM, hand movement; I, insidious; LE, left eye; LP, light perception; m, male; $\mathrm{RE}$, right eye; $\mathrm{S}$, slowly progressive.

Table 2 Data summary of patients included in the UK paediatric LHON cohort

\begin{tabular}{|c|c|c|c|c|c|c|c|c|c|c|c|c|}
\hline \multirow[b]{2}{*}{ Mutation } & \multirow{2}{*}{$\begin{array}{l}\text { Patients } \\
\text { (pedigrees) } \\
\mathrm{n}\end{array}$} & \multicolumn{3}{|c|}{ Sex } & \multirow{2}{*}{$\begin{array}{l}\text { Age at onset } \\
\text { (years) } \\
\text { Mean, Median }\end{array}$} & \multirow{2}{*}{$\begin{array}{l}\text { Acute } \\
\text { onset } \\
\mathrm{n}(\%)\end{array}$} & \multirow{2}{*}{$\begin{array}{l}\text { Slowly } \\
\text { progressive } \\
\text { onset } \\
\text { n (\%) }\end{array}$} & \multirow{2}{*}{$\begin{array}{l}\text { Insidious/ } \\
\text { subclinical } \\
\text { onset } \\
\text { n (\%) }\end{array}$} & \multirow{2}{*}{$\begin{array}{l}\text { Visual } \\
\text { recovery* } \\
\text { n (\%) }\end{array}$} & \multirow{2}{*}{$\begin{array}{l}\text { BCVA } \\
\text { Mean, Median }\end{array}$} & \multirow{2}{*}{$\begin{array}{l}\text { BCVAt } \geq 0.5 \\
n(\%)\end{array}$} & \multirow{2}{*}{$\begin{array}{l}\text { BCVAt }<0.05 \\
n(\%)\end{array}$} \\
\hline & & f & $m$ & $m: f$ & & & & & & & & \\
\hline 11778 & $13(13)$ & 3 & 10 & 3.3 & $6.8,8.0$ & $8(61)$ & $1(7)$ & $4(30)$ & $6(23)$ & $0.20,0.10$ & 5/26 (19) & 9/26 (35) \\
\hline 3460 & $7(7)$ & 2 & 5 & 2.5 & $7.3,7.0$ & $6(86)$ & 0 & 1 (14) & $8(57)$ & $0.60,0.73$ & $8 / 14$ (57) & 2/14 (14) \\
\hline 14484 & $7(4)$ & 2 & 5 & 2.5 & $6.4,6.0$ & $3(29)$ & $3(29)$ & 1 (14) & $6(43)$ & $0.54,0.46$ & $7 / 14$ (50) & $0 / 14(0)$ \\
\hline All & 27 (24) & 7 & 21 & 3.0 & $6.9,7.0$ & $17 / 27(63)$ & $4 / 27(15)$ & $6 / 27(22)$ & 20/54 (37) & $0.39,0.25$ & 20/54 (37) & $11 / 54(20)$ \\
\hline
\end{tabular}

* Number of eyes with visual recovery.

tNumber of eyes with BCVA $\geq 0.5$ or $<0.05$ in Snellen decimal.

BCVA, best corrected visual acuity; f, female; LHON, Leber hereditary optic neuropathy; m, male.

younger $($ mean $=8.5$ years, median $=8.0$ years, range $=3-12$ years) from 20 original publications covering diverse populations: Australia, Brazil, Chile, China, Finland, France, Germany, Italy, Saudi Arabia, Switzerland, the UK and USA (see online supplementary table S1 and online supplementary appendix). The m.11778G $>$ A mutation accounted for $47 / 69$ (69\%) of all the included cases. Visual acuity data were available for 40 patients and overall, 18/79 (23\%) eyes achieved a BCVA $\geq 0.5$ whereas $18 / 79(23 \%)$ eyes achieved a BCVA $<0.05$. We merged the UK paediatric and historical LHON cohorts to generate a meta-analysis of childhood-onset LHON (see online supplementary table S2 and figure S2). The number of patients 


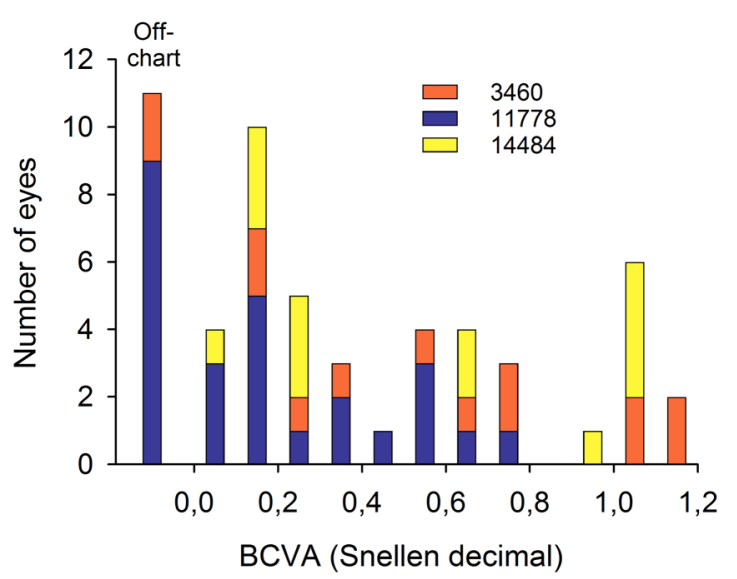

Figure 1 Distribution of best-corrected visual acuity (BCVA) in the UK paediatric Leber hereditary optic neuropathy (LHON) cohort stratified according to the genotype. Off-chart refers to the number of eyes with BCVA worse than 0.05 .

with a BCVA $\geq 0.5$ in at least one eye was 26/67 (39\%) whereas the number of patients with a BCVA $<0.05$ in their better seeing eye was 13/67 (19\%).

\section{DISCUSSION}

LHON is a disease of young adults and due to its relative rarity, there are limited data on the clinical features and visual prognosis of childhood LHON. In this study, we first identified a UK paediatric LHON cohort consisting of 27 patients diagnosed before the age of 12 years, which was then combined with a historical cohort of 69 eligible patients from 20 previously published reports (see online supplementary appendix). These two cohorts had similar clinical and molecular genetic profiles and we therefore combined the data to generate a meta-analysis for a more comprehensive comparison with classical adult-onset LHON.

The distribution of the three major disease-causing LHON mutations (m.3460G $>\mathrm{A}=19 \%$, m.11778G $>\mathrm{A}=62.5 \%$ and m.14484T $>C=19 \%$ ) in the childhood cohort is comparable with previously reported adult LHON case series with the m.11778G > A mtDNA mutation being the most common genotype. As expected, there was a male preponderance, but the overall male:female ratio of 1.8 is less marked than the fourfold

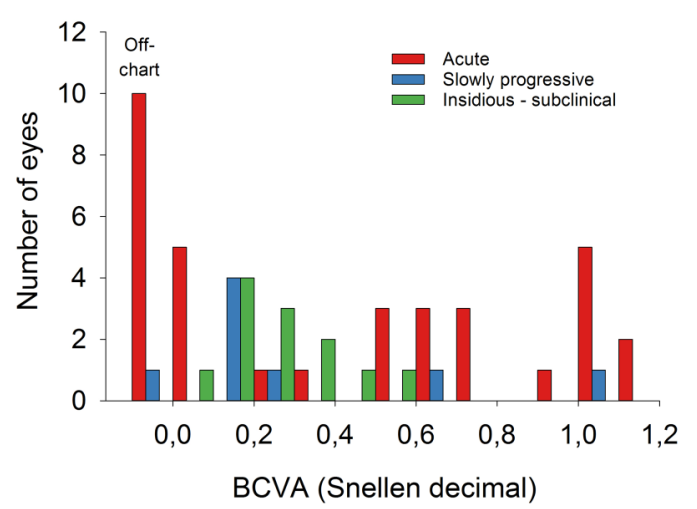

Figure 2 Distribution of best-corrected visual acuity (BCVA) in the UK paediatric Leber hereditary optic neuropathy (LHON) cohort stratified according to the pattern of visual loss at disease onset. Off-chart refers to the number of eyes with BCVA worse than 0.05 . to fivefold increased risk of visual loss seen among adult male carriers. ${ }^{13}{ }^{14}$ The mechanisms contributing to this rather intriguing male bias are not fully understood and a number of secondary genetic, hormonal and environmental risk factors have been implicated. ${ }^{15}$ Smoking and to a lesser extent heavy drinking are regarded as important environmental triggers, but these factors are unlikely to be aetiologically important in young children. Although this hypothesis needs to be formally verified, the less pronounced sex bias in childhood LHON could arise because it is more heavily genetically determined by nuclear modifiers, which contribute to an earlier age of onset, but that are less sex determined or influenced. The other phenotypical extreme would be late-onset adult cases over the age of 50 years where environmental risk factors, in particular smoking, are thought to play a more prominent role in precipitating disease conversion. ${ }^{1617}$ A systematic genomic comparison of childhood LHON, classical acute cases in young adults and late-onset LHON could therefore prove the key to dissecting the complex genetic-environmental modulators that contribute to visual loss in different groups of susceptible carriers.

The classical acute pattern of vision loss was the most common presentation in childhood LHON, but over a third of patients either had a slowly progressive onset or even more strikingly, a subclinical or insidious disease evolution. In a previous report of 14 children with LHON from Barboni and colleagues, the 6 patients classified as having a slowly progressive course achieved better final visual acuities compared with the acute group. ${ }^{7}$ In contrast with this finding, the four patients in the UK paediatric LHON cohort did not have a better prognosis, with the vision deteriorating in the majority of eyes to less than the driving standards, that is, BCVA $<0.5$. The insidious/ subclinical LHON subgroup was observed with all three major disease-causing mtDNA mutations and the defining observation was the significant delays in reaching a confirmed molecular diagnosis, which ranged from 3 years to 15 years. Visually asymptomatic children in whom subnormal vision and optic atrophy, which can be subtle, are detected incidentally have been reported previously and the diagnostic challenges are likely to be multifactorial. ${ }^{10}{ }^{18}$ Visual performance in this age group is not always impaired due to the inherent adaptive capacity of young children and importantly, they may not be able to communicate changes in their vision effectively to their parents or guardians. A lack of clinical awareness of LHON in young children is also likely to be relevant in explaining the diagnostic delays in this patient group.

LHON has a major impact on quality of life and the majority of patients will remain within the criteria for legal blindness. ${ }^{19}$ The observed overall rates of spontaneous visual recovery of $37 \%$ for all eyes in the entire UK paediatric LHON cohort and of $59 \%$ for the eyes of patients with acute LHON, are in line with the corresponding values of $28 \%$ and $63 \%$ reported by Barboni and colleagues. ${ }^{7}$ Patients with adult-onset LHON harbouring the m.14484T $>\mathrm{C}$ mutation have the best visual prognosis with a partial visual recovery rate of 37\%-58\% compared with $4 \%-25 \%$ for the m.11778G $>$ A mutation and $22 \%-25 \%$ for the m.3460G $>$ A mutation. ${ }^{6}{ }^{8}{ }^{20-22}$ The variations in the reported rates of spontaneous visual recovery reflect possible sampling bias depending on the cohort size and the different criteria used to define a visually significant change in visual acuity from the nadir. ${ }^{3}$ In our study, the rates of spontaneous visual recovery were $57 \%, 23 \%$ and $43 \%$ for the $\mathrm{m} .3460 \mathrm{G}>\mathrm{A}$, m.11778G $>\mathrm{A}$ and m.14484T $>\mathrm{C}$ mutations, respectively. Children carrying the $\mathrm{m} .3460 \mathrm{G}>\mathrm{A}$ mutation therefore seem to have a better visual prognosis, and the recovery rate observed 
with the m.11778G $>$ A mutation is also higher, compared with the clinical impression in patients with adult-onset LHON. ${ }^{6} 21$ Based on our meta-analysis of 67 patients for whom visual acuity data were available, $39 \%$ of patients achieved a BCVA $\geq 0.5$ in at least one eye whereas $19 \%$ of patients had a BCVA $<0.05$ in their better seeing eye. A more favourable final visual outcome was observed for all three genotypes in our childhoodonset LHON cohort compared with previously published figures $(\mathrm{m} .3460 \mathrm{G}>\mathrm{A}$ : $14 \%$ vs $55 \%-96 \%$; m. $11778 \mathrm{G}>\mathrm{A}: 45 \%$ vs $73 \%-98 \%$; and $\mathrm{m} .14484 \mathrm{~T}>\mathrm{C}$ mutation: $6 \%$ vs $30 \%-50 \%$ of eyes achieving a BCVA <0.1). ${ }^{1} 682021$ Mitochondrial turnover is implicated in the pathogenesis of LHON, both mitochondrial biogenesis and mitophagy being increased in fibroblasts of patients with LHON. ${ }^{23}{ }^{24}$ The known age-related decline in mitophagy, and hence presumably mitochondrial biogenesis, may underlie this difference from adult disease. ${ }^{25}$

In conclusion, childhood-onset LHON represents a distinct phenotypical subgroup characterised by a more varied clinical evolution and a more favourable visual prognosis compared with classical adult LHON. Importantly, children do not always develop acute or subacute visual symptoms and a high index of suspicion is required in children presenting with unexplained subnormal vision and optic disc pallor to avoid potentially long diagnostic delays.

\author{
Author affiliations \\ ${ }^{1}$ UCL Institute of Ophthalmology, London, UK \\ ${ }^{2}$ Moorfields Eye Hospital, London, UK \\ ${ }^{3}$ Department of Ophthalmology, Helsinki University Hospital, and University of \\ Helsinki, Helsinki, Finland \\ ${ }^{4}$ Great Ormond Street Hospital, London, UK \\ ${ }^{5}$ Nuffield Department of Obstetrics \& Gynaecology, University of Oxford, Oxford, UK \\ ${ }^{6}$ Department of Ophthalmology, Royal United Hospital, Bath, UK \\ ${ }^{7}$ Wellcome Trust Centre for Mitochondrial Research, Institute of Genetic Medicine, \\ Newcastle University, Newcastle upon Tyne, UK \\ ${ }^{8}$ Medical Research Council Mitochondrial Biology Unit, Cambridge, UK \\ ${ }^{9}$ Department of Clinical Neurosciences, School of Clinical Medicine, University of \\ Cambridge, Cambridge, UK \\ ${ }^{10}$ School of Optometry and Vision Sciences, Cardiff University and Cardiff Eye Unit, \\ University Hospital Wales, Cardiff, UK \\ ${ }^{11}$ Ophthalmology Department, UCSF School of Medicine, San Francisco, California, \\ USA \\ ${ }^{12}$ Newcastle Eye Centre, Royal Victoria Infirmary, Newcastle upon Tyne, UK
}

Contributors Research design: AM, MV, ATM, PY-W-M. Data acquisition and/or research execution: AM, RB, JP, RJA, MAR, MM, ARW, MV, ATM, PY-W-M. Data analysis and/or interpretation: AM, PFC, MV, ATM, PY-W-M. Manuscript preparation: AM, PY-W-M

Funding This research was supported by the National Institute for Health Research Rare Diseases Translational Research Collaboration (NIHR RD-TRC) and the National Institute for Health Research Biomedical Research Centre at Moorfields Eye Hospital National Health Service Foundation Trust and UCL Institute of Ophthalmology, the NIHR Moorfields Clinical Research Facility. AM receives funding from Suomen Silmätutkimusseura ry:n Apurahasäätiö (Finland). MV and PY-W-M receive funding from Fight for Sight (UK). ATM, MV, PFC and PY-W-M receive funding from the UK National Institute of Health Research (NIHR) as part of the Rare Diseases Translational Research Collaboration. PY-W-M is supported by a Clinician Scientist Fellowship Award (G1002570) from the Medical Research Council (UK). PFC is a Wellcome Trust Senior Fellow in Clinical Science (101876/Z/13/Z), and a UK NIHR Senior Investigator, who receives support from the Medical Research Council Mitochondrial Biology Unit (MC_UP_1501/2), the Wellcome Trust Centre for Mitochondrial Research (096919Z/11/Z), the Medical Research Council (UK) Centre for Translational Muscle Disease (G0601943). JP was funded by the MRC (MR/ J010448/1) and the Wellcome Trust (0948685/Z/10/Z) and has salary support from the NHS specialised Services Rare Mitochondrial Disorders Service.

Competing interests PY-W-M holds a consultancy agreement with GenSight Biologics (Paris, France).
Ethics approval The ethics committee at Moorfields Eye Hospital, London, UK.

Provenance and peer review Not commissioned; externally peer reviewed.

\section{REFERENCES}

1 Nikoskelainen EK, Huoponen K, Juvonen V, et al. Ophthalmologic findings in Leber Hereditary Optic Neuropathy, with special reference to mtDNA mutations. Ophthalmology 1996;103:504-14.

2 Yu-Wai-Man P, Chinnery PF. Leber Hereditary Optic Neuropathy. In: Pagon RA, Adam MP, Ardinger HH, et al. eds. GeneReviews $®$ [Internet]. Seattle, WA: University of Washington, Seattle, 1993-2016. 2000 Oct 26 (updated 2013 Sep 19).

3 Yu-Wai-Man P, Votruba M, Moore AT, et al. Treatment strategies for inherited optic neuropathies — past, present and future. Eye (Lond) 2014;28:521-37.

4 Mackey DA, Oostra RJ, Rosenberg T, et al. Primary pathogenic mtDNA mutations in multigeneration pedigrees with Leber hereditary optic neuropathy. Am J Hum Genet 1996;59:481-5

5 Bosley TM, Brodsky MC, Glasier CM, et al. Sporadic bilateral optic neuropathy in children: the role of mitochondrial abnormalities. Invest Ophthalmol Vis Sci 2008:49:5250-6.

6 Newman NJ, Lott MT, Wallace DC. The clinical characteristics of pedigrees of Leber's hereditary optic neuropathy with the 11778 mutation. Am J Ophthalmol 1991;111:750-62.

7 Barboni P, Savini G, Valentino ML, et al. Leber's hereditary optic neuropathy with childhood onset. Invest Ophthalmol Vis Sci 2006:47:5303-9.

8 Johns DR, Smith KH, Miller NR. Leber's hereditary optic neuropathy: clinical manifestations of the 3460 mutation. Arch Ophthalmol 1992;110:1577-81.

9 Mackey D, Howell N. A variant of Leber hereditary optic neuropathy characterized by recovery of vision and by an unusual mitochondrial genetic etiology. Am J Hum Genet 1992;51:1218-28

10 Pezzi PP, De Negri AM, Sadun F, et al. Childhood Leber's hereditary optic neuropathy (ND1/3460) with visual recovery. Pediatr Neurol 1998;19:308-12.

11 Majander A, Bitner-Glindzicz M, Chan CM, et al. Lamination of the outer plexiform layer in optic atrophy caused by dominant WFS1 mutations. Ophthalmology 2016;123:1624-6.

12 Yu-Wai-Man P, Bailie M, Atawan A, et al. Pattern of retinal ganglion cell loss in dominant optic atrophy due to OPA1 mutations. Eye (Lond) 2011;25:596-602.

13 Puomila A, Hämäläinen $\mathrm{P}$, Kivioja $\mathrm{S}$, et al. Epidemiology and penetrance of Leber hereditary optic neuropathy in Finland. Eur J Hum Gen 2007;15:1079-89.

14 Black GC, Craig IW, Oostra RJ, et al. Leber's hereditary optic neuropathy: implications of the sex ratio for linkage studies in families with the 3460 ND1 mutation. Eye (Lond) 1995;9(Pt 4):513-16.

15 Kirkman MA, Yu-Wai-Man P, Korsten A, et al. Gene-environment interactions in Leber hereditary optic neuropathy. Brain 2009;132:2317-26.

16 Carelli V, d'Adamo P, Valentino ML, et al. Parsing the differences in affected with LHON: genetic versus environmental triggers of disease conversion. Brain 2016;139 (Pt 3):e17.

17 Yu-Wai-Man P, Hudson G, Klopstock T, et al. Reply: parsing the differences in affected with LHON: genetic versus environmental triggers of disease conversion. Brain 2016;139(Pt 3):e18.

18 Moorman CM, Elston JS, Matthews P. Leber's hereditary optic neuropathy as a cause of severe visual loss in childhood. Pediatrics 1993;91:988-9.

19 Kirkman MA, Korsten A, Leonhardt M, et al. Quality of life in patients with Leber hereditary optic neuropathy. Invest Ophthalmol Vis Sci 2009;50:3112-15.

20 Johns DR, Heher KL, Miller NR, et al. Leber's hereditary optic neuropathy. Clinical manifestations of the 14484 mutation. Arch Ophthalmol 1993;111:495-8.

21 Riordan-Eva P, Sanders MD, Govan GG, et al. The clinical features of Leber's hereditary optic neuropathy defined by the presence of a pathogenic mitochondrial DNA mutation. Brain 1995;118(Pt 2):319-37.

22 Lam BL, Feuer WJ, Schiffman JC, et al. Trial end points and natural history in patients with G11778A Leber hereditary optic neuropathy: preparation for gene therapy clinical trial. JAMA Ophthalmol 2014;132:428-36.

23 Giordano C, Iommarini L, Giordano L, et al. Efficient mitochondrial biogenesis drives incomplete penetrance in Leber's hereditary optic neuropathy. Brain 2014;137:335-53.

24 Dombi E, Diot A, Morten K, et al. The m.13051G>A mitochondrial DNA mutation results in variable neurology and activated mitophagy. Neurology 2016;86:1921-3.

25 Diot A, Hinks-Roberts A, Lodge T, et al. A novel quantitative assay of mitophagy: combining high content fluorescence microscopy and mitochondrial DNA load to quantify mitophagy and identify novel pharmacological tools against pathogenic heteroplasmic mtDNA. Pharmacol Res 2015;100:24-35. 


\section{Childhood-onset Leber hereditary optic neuropathy}

Anna Majander, Richard Bowman, Joanna Poulton, Richard J Antcliff, M Ashwin Reddy, Michel Michaelides, Andrew R Webster, Patrick F

Chinnery, Marcela Votruba, Anthony T Moore and Patrick Yu-Wai-Man

Br J Ophthalmol 2017 101: 1505-1509 originally published online March 17,2017

doi: 10.1136/bjophthalmol-2016-310072

Updated information and services can be found at:

http://bjo.bmj.com/content/101/11/1505

\section{These include:}

References This article cites 24 articles, 4 of which you can access for free at: http://bjo.bmj.com/content/101/11/1505\#BIBL

Email alerting service

Receive free email alerts when new articles cite this article. Sign up in the box at the top right corner of the online article.

Topic Articles on similar topics can be found in the following collections

Collections

Open access (273)

\section{Notes}

To request permissions go to:

http://group.bmj.com/group/rights-licensing/permissions

To order reprints go to:

http://journals.bmj.com/cgi/reprintform

To subscribe to BMJ go to:

http://group.bmj.com/subscribe/ 